\title{
Moisture diffusion coefficients determination of furan bonded sands and water based
} foundry coatings

\section{Di Muoio, Giovanni Luca; Tiedje, Niels Skat}

Published in:

The International Journal of Cast Metals Research

Link to article, DOI:

10.1179/1743133615Y.0000000038

Publication date:

2016

Document Version

Peer reviewed version

Link back to DTU Orbit

Citation (APA):

Di Muoio, G. L., \& Tiedje, N. S. (2016). Moisture diffusion coefficients determination of furan bonded sands and water based foundry coatings. The International Journal of Cast Metals Research, 29(3), 121-128.

https://doi.org/10.1179/1743133615Y.0000000038

\section{General rights}

Copyright and moral rights for the publications made accessible in the public portal are retained by the authors and/or other copyright owners and it is a condition of accessing publications that users recognise and abide by the legal requirements associated with these rights.

- Users may download and print one copy of any publication from the public portal for the purpose of private study or research.

- You may not further distribute the material or use it for any profit-making activity or commercial gain

- You may freely distribute the URL identifying the publication in the public portal 


\title{
Moisture Diffusion Coefficients Determination of Furan Bonded Sands and Water Based Foundry Coatings
}

\author{
Giovanni Luca Di Muoio*, \\ Global Castings A/S, Copenhagen, Denmark \\ Niels Skat Tiedje, \\ Technical University of Denmark, Copenhagen, Denmark
}

\begin{abstract}
*Corresponding author: gidmu@globalcastings.com, M: +45 6180 9266, Global Castings A/S, 373 N Diplomvej, Lyngby, 2800,
\end{abstract}

Moisture content in furan bonded sand and water based coatings can be one of the main causes for gas related defects in large cast iron parts. Moisture diffusion coefficients for these materials are needed to precisely predict the possible moisture levels in foundry moulds. In this study, we first compare two different experimental methods that can be used to determine moisture diffusion coefficients. Then, we determine diffusion coefficients for water based coatings and for different types of furan binders and we investigate the effects of compaction, dust levels and temperature. Finally, we provide an example on how it is possible to apply this knowledge to estimate moisture variation in a sand mould during production.

\section{Keywords}

Moisture diffusion coefficients, furan sand, water based foundry coating, vapour sorption analysis, core drying.

\author{
List of Symbols \\ D diffusion coefficient $\left[\mathrm{m}^{2} \mathrm{~s}^{-1}\right]$ \\ $L$ thickness of the sample $[\mathrm{m}]$ \\ $M_{t}$ adsorbed mass of water at time $t[k g]$ \\ $M_{e}$ adsorbed mass of water at equilibrium [kg] \\ t time $[s]$ \\ $\mathrm{x}$ space $[\mathrm{m}]$
}




\author{
$\mathrm{X}$ moisture [ ] \\ $\mathrm{X}_{\mathrm{i}}$ initial moisture content [\%] \\ $\mathrm{X}_{\mathrm{e}}$ moisture content at equilibrium [ ] \\ $\mathrm{X}_{\mathrm{t}}$ moisture content at time $\mathrm{t}[\mathrm{]}$ \\ $\mathrm{X}^{*}$ nondimensional moisture [ ]
}

\title{
1 - Introduction
}

Residual moisture in moulds and foundry coatings can be responsible for generating gases that lead to the formation of different kinds of defects such as hydrogen pin holes, blow holes, cracks and explosive penetrations (as shown in figure 1) [1-3]. These defects can lead to non-conformities or, eventually, to a scraped casting and therefore and to an increase in production cost. Moisture present in moulds and core is an important contributor to the generation of gases (and related defects) during the pouring of liquid metal [3-5].

Foundry moulding and coating materials contain moisture and they can adsorb or release it in different amounts and at different speeds. The equilibrium moisture levels and the effects of different factors, such as dust amount, binder type and temperature, for different furan sands and foundry coating have been investigated in [6].

With regard to the adsorption rate of moisture, the critical parameter needed to model this behaviour is the moisture diffusion coefficient [7]. Such coefficient, typically obtained from laboratory tests, is needed in order to predict more precisely how the moisture distribution in a mould changes when conditions in the surrounding environment are varying. For example, foundry cores and moulds are exposed to a varying environment for different time after drying in a drying cabinet at low $\mathrm{RH}$ and high temp (figure 2).

In the drying industry moisture diffusion coefficients are used to design driers used mainly in food and wood industry [7]. Determining the coefficients is done with different methods in different industries [7-13]. Data for moisture diffusivity coefficients is available for general classes of materials (like wood, milk, paper, sand, etc...) [7] but not for materials used in the foundry industry like furan sands and water based coatings.

Literature shows that the moisture diffusion coefficient can be affected by many factors (like temperature and moisture) [7] and also by methods used to obtain and analyse the data [8].

In this study, we present results from gravimetric moisture adsorption tests on which an analytical solution of the diffusion equation is fitted. The objective to estimate moisture diffusion coefficients and the effect of different factors on the moisture diffusion of furan bonded sands and of water based coatings. The variables investigated in this study are sand compaction, air relative humidity, temperature, dust content and binder type. Two possible test methods are compared and evaluated. 
Finally, an example of how it is possible to use these coefficient for the estimation of moisture in a foundry moulds is provided.

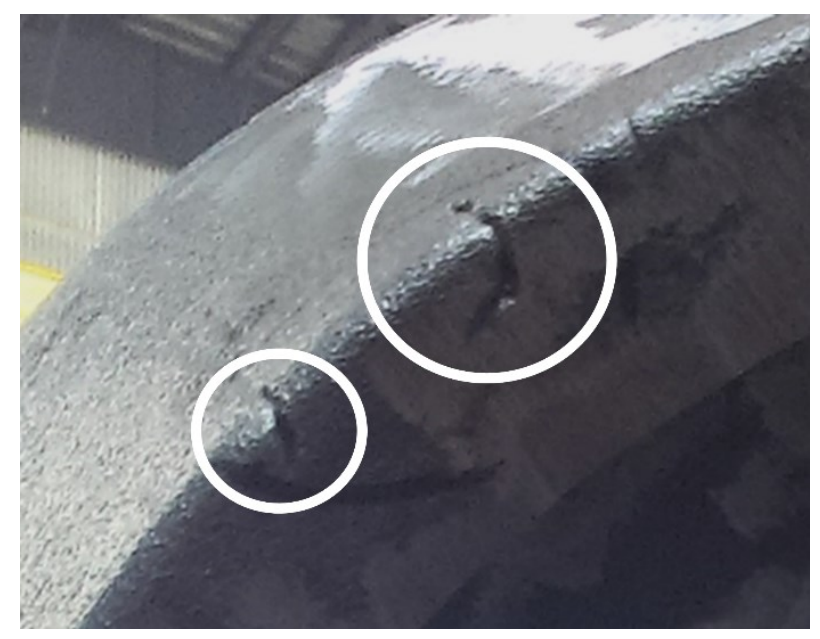

Figure 1. Example of Moisture Related Defect.

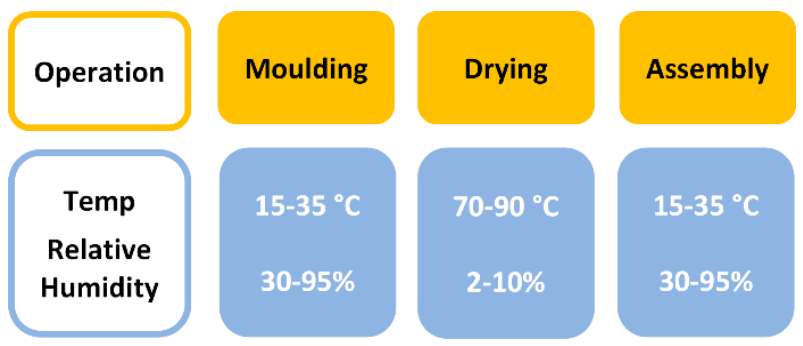

Figure 2. Production process steps for a furan sand mould coated with water based coating and correspondent ranges of environment conditions.

\section{2 - Methods}

Two different methods were used to run moisture adsorption tests. A manual method, in which a simple (but slow), low cost equipment is used and an automatic test methodology (Automatic Vapour Sorption Analysis) where more costly (but faster) equipment is used. In this way, it will be possible not only to determine the diffusion coefficient, but also to compare the results from the two methods and give recommendations to the foundry industry on which test methods to use to estimate moisture diffusion coefficients.

\section{$\underline{2.1 \text { - Manual Tests }}$}

In the manual tests method furan sand samples are moulded in a cylindrical mould of $18 \mathrm{~mm}$ diameter and $50 \mathrm{~mm}$ depth. 
In order to represent the possible ranges of density of a real production mould, some mould are left un-compacted, while on the others a $1 \mathrm{~kg}$ weight is added right after filling as shown in figure 3 (more details on the preparation and compaction procedure can be found in [14]). In this way, it will be possible to achieve different sand density of the samples and to determine the possible effect on the moisture diffusion coefficients.

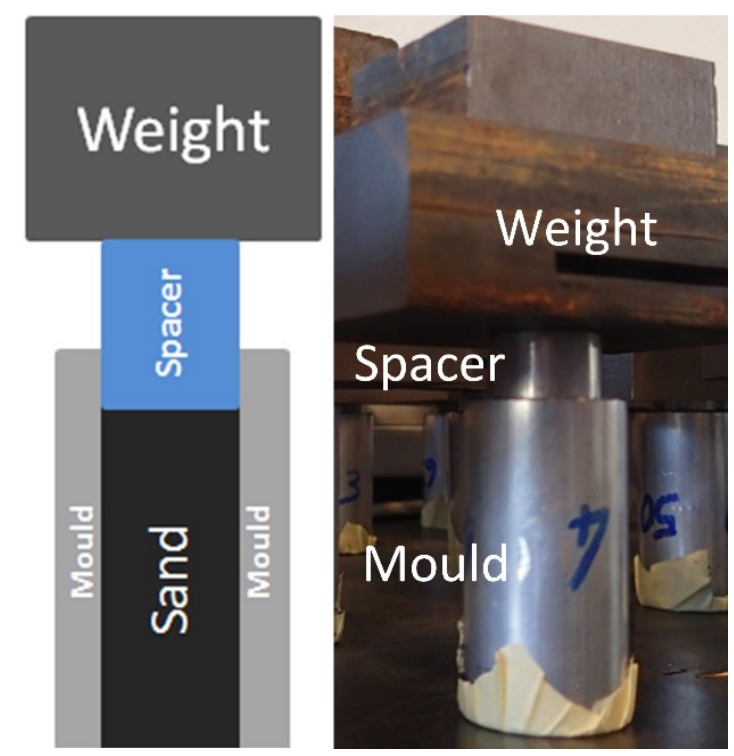

Figure 3. Sample Preparation for manual adsorption tests.

Samples are cured for 48 hours at room conditions $\left(23-25^{\circ} \mathrm{C}\right.$ and $\left.35-45 \% \mathrm{RH}\right)$, followed by a period of equilibration of 48 hours where samples are placed in a sealed container where silica gel is used to keep air relative humidity at $5-7 \%$. In this way, we equilibrate the moisture of the sample to replicate the situation of a mould which has been through a drying step as shown in figure 2 .

After equilibration at $5 \% \mathrm{RH}$, the sample is placed on a precision scale connected to computer that records weight changes. The air around the sample will be either at laboratory conditions (23$25^{\circ} \mathrm{C}$ and $35-45 \% \mathrm{RH}$ ) or near saturation $\left(23-25^{\circ} \mathrm{C}\right.$ and $\left.95 \% \mathrm{RH}\right)$. In order to achieve the $95 \% \mathrm{RH}$ test condition, a water soaked cloth is added on the wall of the sample chamber (figure 4).

This procedure is aiming at reproducing the process of a mould taken out from a drying step and placed in environment where the humidity can vary from 30 to $95 \% \mathrm{RH}$ (as shown in figure 2). However due to limitations of the manual method, only the two above described values of relative humidity are used in these experiments. 


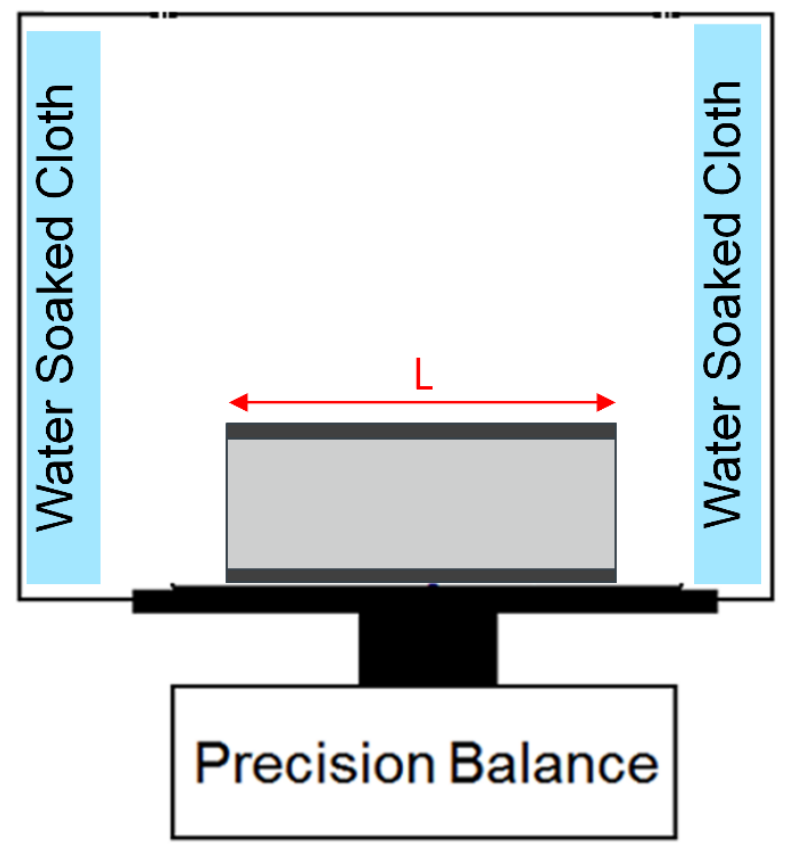

Figure 4. Schematic test setup for manual sorption tests.

The experimental plan for manual tests can be summarised as in Table 1 where two possible sand binder recipes (GCK and GCM) were tested at two humidity levels.

The plan is repeated for low and high compaction sample and replicated two times, for a total of 16 runs.

Table 1. Overview of experimental plan for manual sorption tests.

\begin{tabular}{|c|c|c|}
\hline \multirow{2}{*}{ Material } & \multicolumn{2}{|c|}{ Temperature $\left[{ }^{\circ} \mathbf{C}\right.$ ] } \\
\cline { 2 - 3 } & \multicolumn{2}{|c|}{25} \\
\cline { 2 - 3 } & Relative Humidity [\%] \\
\cline { 2 - 3 } & 40 & 95 \\
\hline \hline GCK & $\mathrm{X}$ & $\mathrm{X}$ \\
\hline $\mathrm{GCM}$ & $\mathrm{X}$ & $\mathrm{X}$ \\
\hline
\end{tabular}

The sample moisture can be calculated from the weight variation (Eq.1) and is defined on wet basis as common practice in foundry industry:

$$
X(t)_{\text {w.b. }}=\frac{\text { CurrentWe } \mathrm{g} h t-\text { DryWeight }}{\text { CurrentWeg } h t} 100 \text { Eq.1 }
$$

The dry weight is obtained by drying the sample at $105^{\circ} \mathrm{C}$ for 30 minutes. 


\section{2 - Automatic Tests}

For the automatic tests method, an AquaLab automatic vapour sorption analyser is used. The cured sand samples and dry coating samples are crushed, since it is only possible to test granular material in such equipment, as shown in figure 5.
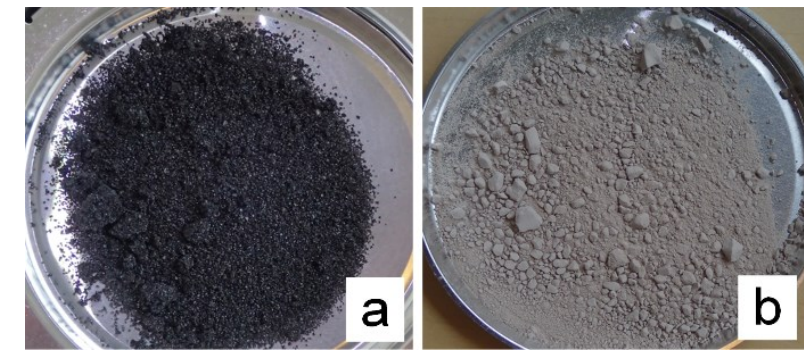

Figure 5. Sample preparation for automatic vapour sorption tests.

Then, the samples are placed in the automatic sorption analyser (Figure 6) and the initial moisture value (obtained from preliminary tests) is entered. The equipment, then, starts to record weight variation as air humidity is varied stepwise from 3 to $95 \% \mathrm{RH}$. In this way it is possible to test the full range of environmental condition to which a sand mould can be subjected in a real factory. 


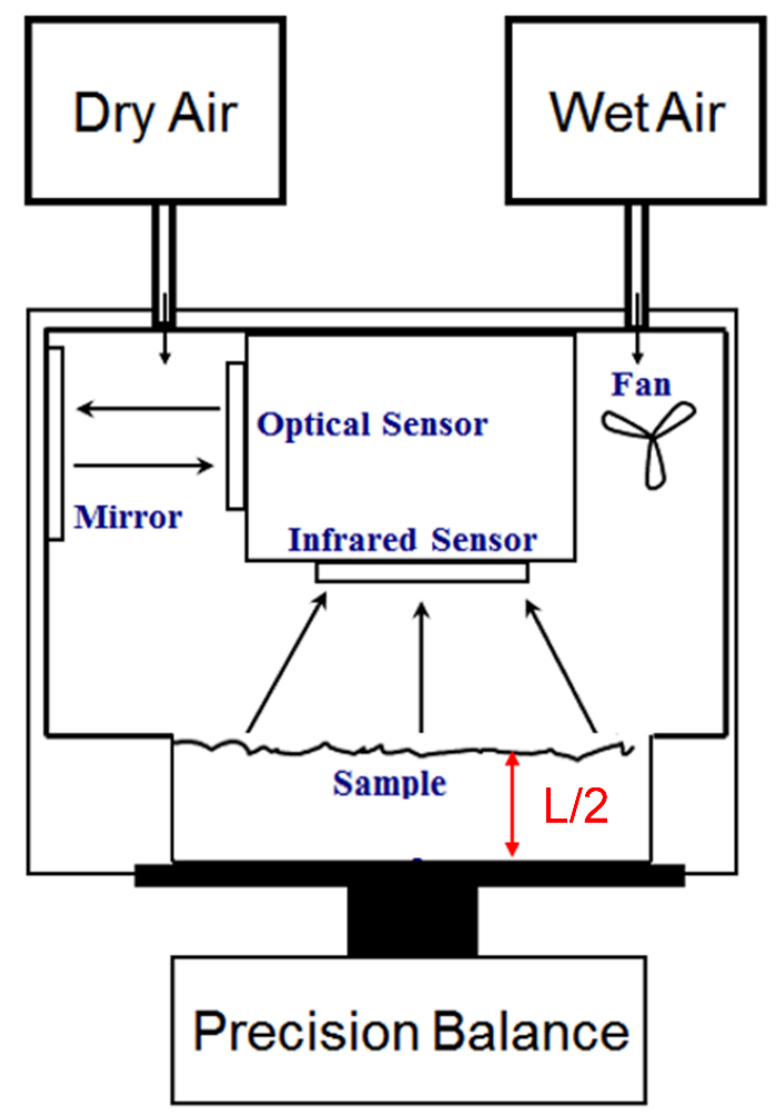

Figure 6. Test setup schematic for automatic sorption tests.

Figure 7 shows a typical data output from an automatic sorption test run. At each test step the relative humidity is kept constant until the mass variation of the sample is less than $0.2 \%$ per hour. At this point the sample is considered to be in equilibrium and the next step starts. More details on the automatic test procedure can be found in [6].

Moisture is calculated on wet basis using Eq. 1 as for the manual tests.

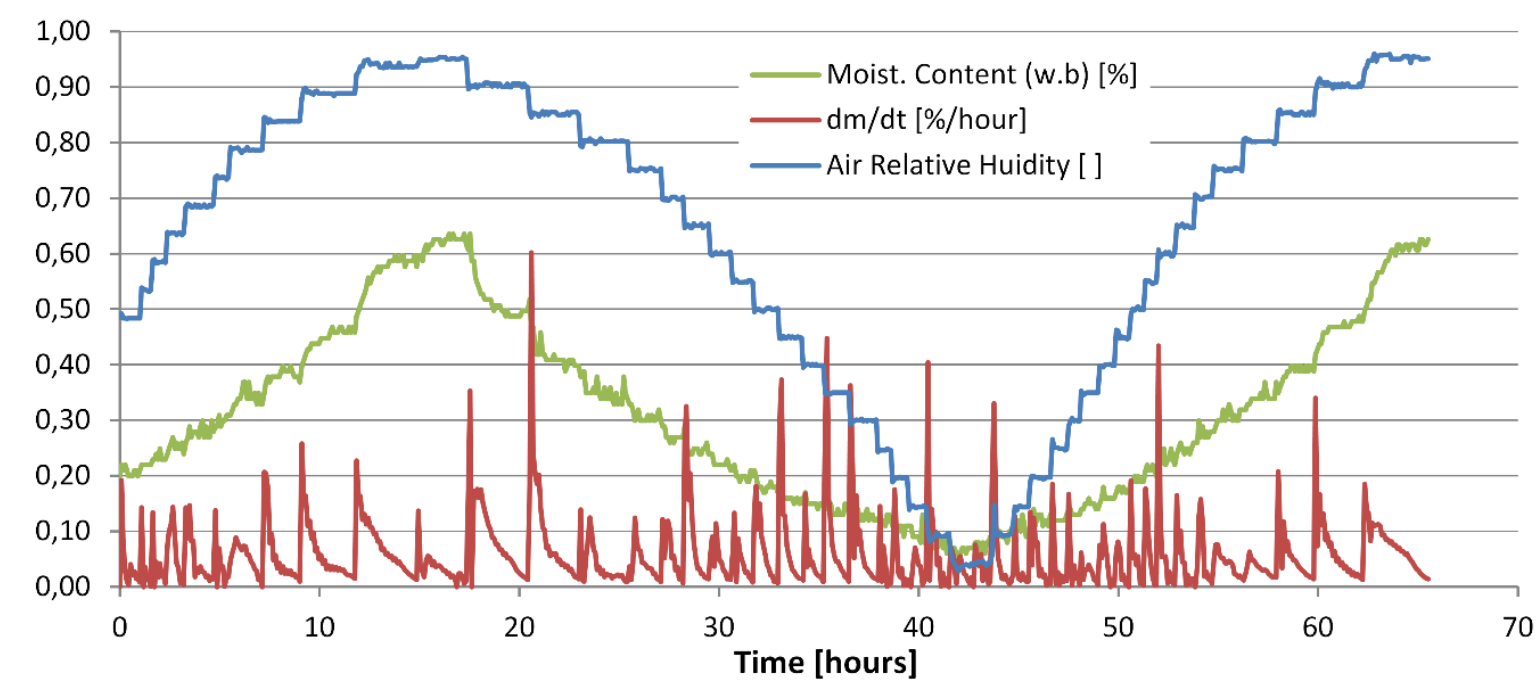


Figure 7. Typical data output from and automatic sorption test run.

Figure 8 shows a typical adsorption/desorption curve, illustrating the equilibrated weight of the sample at different relative humidity during the initialization cycle and during the desorption and adsorption cycle.

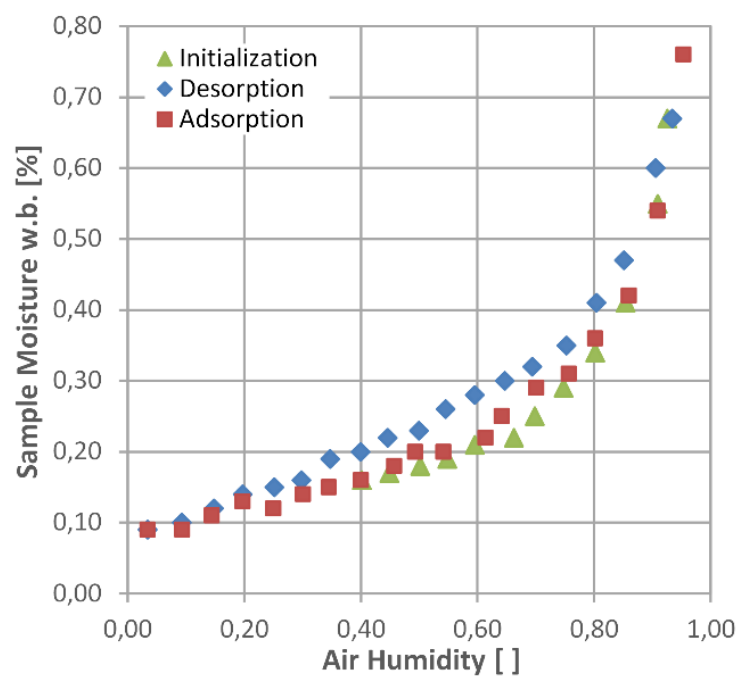

Figure 8. Typical adsorption/desorption curve for furan sand.

The experimental plan for the automatic tests is summarised in Table 2. Tests are carried out at 15 ${ }^{\circ} \mathrm{C}, 25^{\circ} \mathrm{C}$ and $35^{\circ} \mathrm{C}$ for coating and GCX F furan sand. Then at $25^{\circ} \mathrm{C}$ we test effect of dust amount ( 0 and $2 \%$ ) and different brands of furan binders. Pure dust and un-bonded sand are also tested to provide basis for comparison. A total of thirteen sorption tests is carried out.

Table 2. Overview of experimental plan for automatic vapour sorption tests.

\begin{tabular}{|c|c|c|c|}
\hline \multirow{2}{*}{ Material } & \multicolumn{3}{|c|}{ Temperature [ ${ }^{\circ} \mathbf{C}$ ] } \\
\cline { 2 - 4 } & 15 & 25 & 35 \\
\hline \hline Coating & $\mathrm{X}$ & $\mathrm{X}$ & $\mathrm{X}$ \\
\hline GCX F & $\mathrm{X}$ & $\mathrm{X}$ & $\mathrm{X}$ \\
\hline \hline GCK No Dust & & $\mathrm{X}$ & \\
\hline GCK 2\% Dust & & $\mathrm{X}$ & \\
\hline \hline GCX S & & $\mathrm{X}$ & \\
\hline GCM & & $\mathrm{X}$ & \\
\hline GCGG & & $\mathrm{X}$ & \\
\hline \hline Pure Dust & & $\mathrm{X}$ & \\
\hline Un-bonded Sand & & $\mathrm{X}$ & \\
\hline
\end{tabular}




\section{$\underline{2.3-\text { Diffusion Coefficients Determination }}$}

In order to obtain diffusion coefficients from the test data, approximated solutions of the diffusion equation are fitted to the measured weight curves.

The moisture diffusion equation (Eq. 2a) is solved with boundary conditions representative of the one used in the tests $[8,15,16]$.

$$
\frac{\partial X}{\partial t}=D \frac{\partial^{2} X}{\partial t^{2}} \quad \text { Eq. } 2 \mathrm{a}
$$

Initial condition:

$$
X(x, 0)=X_{i} \quad \text { Eq. 2.b }
$$

Boundary conditions on the air side

$$
X(0, t)=X_{f} \quad \text { Eq.2c }
$$

Boundary condition the other air side (manual tests):

$$
X(L, t)=X_{f} \quad \text { Eq2.d }
$$

Boundary Condition at bottom of sample holder (automatic tests):

$$
\left(\frac{\partial X}{\partial x}\right)_{x=\frac{L}{2}}=0 \quad \text { Eq. 2.e }
$$

The next step involves a change of variables to normalise the moisture content as follows:

$$
X^{*}=\frac{X-X_{i}}{X_{e}-X_{i}} \quad \text { Eq.3 }
$$

In this way, for a sample moisture of $X=X_{i}$ the normalised moisture $X^{*}$ will have a value of zero. On the other hand, for a sample moisture of $X=X_{e}$ the normalised moisture value $X^{*}$ will be 1 .

For the manual sorption tests, nondimensionalization is applied so that for each test initial moisture $X_{i}$ is equal to the equilibrated moisture at $5 \% \mathrm{RH}$ and the final moisture $\mathrm{X}_{\mathrm{e}}$ is the equilibrated moisture value reached at the specific test relative humidity ( $40 \%$ or $95 \% \mathrm{RH})$.

For the automatic sorption test, the nondimensionalization is carried out for each test step (time for which the relative humidity is kept constant). The initial moisture $X_{i}$ is the initial moisture of the sample at the specific test step and the final moisture $X_{e}$ is the final equilibrated moisture at the specific test step. In this way it is possible to obtain a diffusion coefficient for each value of relative humidity used in test steps. 
The full form of the analytical solution of the moisture distribution for the above problem is reported in several works $[10,15,16]$. An integration of the analytical solution of the moisture distribution over the thickness of the test sample is carried out to obtain the mass of the sample.

Finally, the solution is expressed in a ratio between the adsorbed mass of water by the sample at the time $t\left(\mathrm{M}_{\mathrm{t}}\right)$ and the equilibrated mass of the sample $\mathrm{M}_{\mathrm{e}}$ and approximated as below $[15,16]$ :

$\frac{M_{t}}{M_{e}}=\frac{4}{L} \sqrt{\frac{D t}{\pi}} \quad$ for $\frac{M_{t}}{M_{e}}<0.5$ Eq.4a

$\frac{M_{t}}{M_{e}}=1-\frac{8}{\pi^{2}} \exp \left(-\frac{\pi^{2} D}{L^{2}} t\right)$ for $\frac{M_{t}}{M_{e}}>0.5$ Eq.4b

Where $D$ is the diffusion coefficient and $L$ the thickness of the sample as shown in figures 4 and 6. Both approximations of the solution must fit experimental data in the correspondent range of $\mathrm{M}_{\mathrm{t}} / \mathrm{M}_{\mathrm{e}}$ using the same diffusion coefficient (Figure 9).

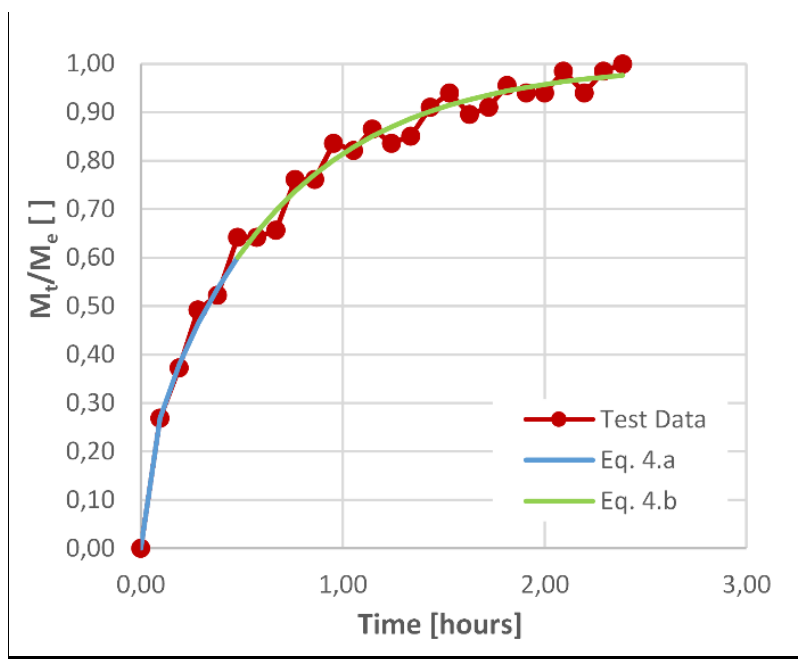

Figure 9. Example of experimental data fitted with the two approximated solutions Eq.4a and Eq4.b.

\section{3 - Results and Discussion}

In the following sections first we present the diffusion coefficients obtained from the different tests, then we show how we use them to estimate the moisture in a foundry mould.

\section{$\underline{3.1 \text { - Diffusion coefficients }}$}

We start by looking at all the results obtained from the manual tests (Figure 10).

The first large effect that we notice is the one of relative humidity. For example, in the tests carried out at $95 \% \mathrm{RH}$ on GCM sand we have moisture coefficients values of about $1,00 \mathrm{E}-8 \mathrm{~m}^{2} / \mathrm{s}$, 
while for the same sand tested at $40 \% \mathrm{RH}$ the moisture diffusion coefficient increases to around $2,40 \mathrm{E}-8 \mathrm{~m}^{2} / \mathrm{s}$.

The second effect that we see is the one of binder type. If we consider GCM sand at $40 \% \mathrm{RH}$ the diffusion coefficient is around $2.40 \mathrm{E}-8 \mathrm{~m}^{2} / \mathrm{s}$ while for GCK sand at $40 \% \mathrm{RH}$ the diffusion coefficient drops to around $1.80 \mathrm{E}-8 \mathrm{~m}^{2} / \mathrm{s}$.

As in regard to compaction effect, in the range of density considered there is a small effect for very low densities. For example GCK sand tested at $40 \% \mathrm{RH}$ has diffusion coefficient of $1.2 \mathrm{E}-8 \mathrm{~m}^{2} / \mathrm{s}$ at a density $1140 \mathrm{~kg} / \mathrm{m}^{3}$ while the other test samples are scattered around $1.00 \mathrm{E}-8 \mathrm{~m} / \mathrm{s}$. For density between $1250 \mathrm{~kg} / \mathrm{m}^{3}$ and $1550 \mathrm{~kg} / \mathrm{m}^{3}$ there seem to be no appreciable effect of density on the moisture diffusion coefficients values.

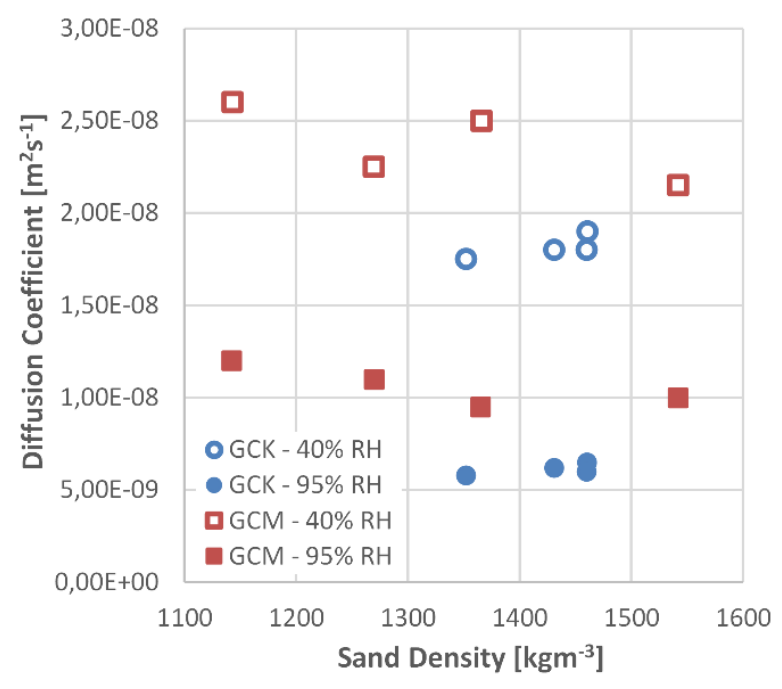

Figure 10. Density effect on moisture diffusion coefficient obtained with manual test method.

Figure 11 compares the results from automatic tests and manual tests.

As in regards to the agreement between the results from automatic and sorption tests, we see that there good agreement for the tests at $40 \% \mathrm{RH}$, but for the tests at $95 \%$ the manual tests slight overestimating the diffusion coefficients. This error is probably due to the fact that, since the moisture diffusion coefficients are not constant with relative humidity (as see confirmed by both tests), the value obtained from testing at $95 \%$ starting from a sample equilibrated at $5 \%$ will be influenced by the values of the diffusion coefficient at the intermediate relative humidifies.

For both materials we see that the strong effect of relative humidity is confirmed also for the automatic tests. In particular, for relative humidity below $60 \%$ the diffusion coefficients show little variation, while there is sharp increase for humidity above $60 \%$.

The binder effect is also shown clearly by the automatic tests.

If we compare the obtained values $\left(4.00 \mathrm{E}-9 \mathrm{~m}^{2} / \mathrm{s}\right.$ to $\left.2.7 \mathrm{E}-8 \mathrm{~m}^{2} / \mathrm{s}\right)$ to the ones available in literature [7] for somewhat similar ceramic material like concrete $\left(5.0 \mathrm{E}-10 \mathrm{~m}^{2} / \mathrm{s}\right.$ to $\left.1.2 \mathrm{E}-8 \mathrm{~m}^{2} / \mathrm{s}\right)$, clay brick 
$\left(1.3 \mathrm{E}-8 \mathrm{~m}^{2} / \mathrm{s}\right.$ to $\left.1.4 \mathrm{E}-8 \mathrm{~m}^{2} / \mathrm{s}\right)$ and sand $\left(8.0 \mathrm{E}-8 \mathrm{~m}^{2} / \mathrm{s}\right.$ to $\left.1.5 \mathrm{E}-7 \mathrm{~m}^{2} / \mathrm{s}\right)$ we see that they are comparable.

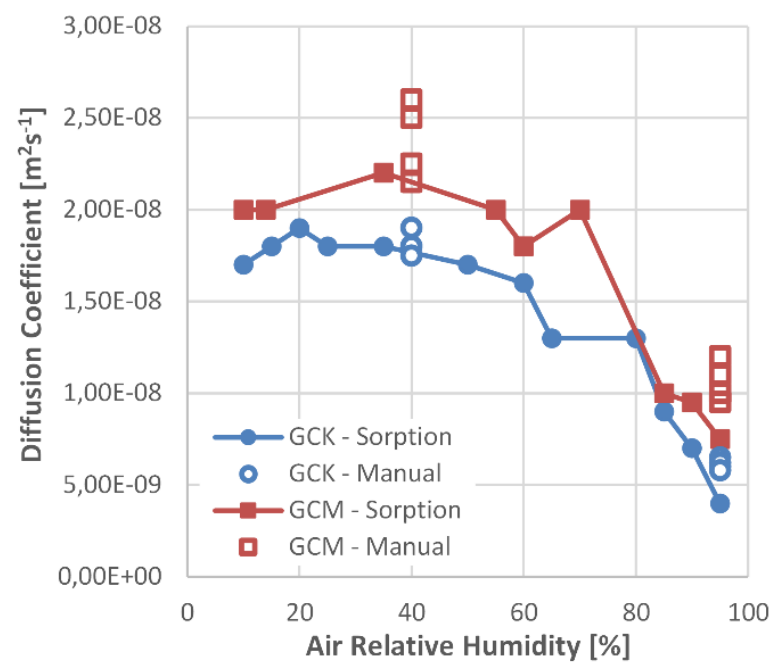

Figure 11. Effect of test method and air relative humidity on moisture diffusion coefficient of GCK and GCM furan sands.

Figure 12.a shows the results obtained for different furan binder brands. We can see for example how some binders (like GCXS, GCGG and GCM) have a higher moisture diffusivity than other at low relative humidity value. On the other hand, for higher relative humidity value the differences between different binders behaviour becomes smaller.

It is also interesting to note how. for unbounded sand, we have the highest diffusion coefficients value (up to $3.1 \mathrm{E}-8 \mathrm{~m}^{2} / \mathrm{s}$ ) that decrease linearly for increasing relative humidity, while, for bonded sands, we have an nonlinear relation between diffusion coefficient values and relative humidity. These behaviours are in line with results found in [6] where we show that sand moisture content increases linearly with relative humidity and is quite low, while binder have a higher moisture content and a non-linear sorption curve.

With regard to the effect of dust content, in Figure 12.b we see that pure dust has lower diffusion coefficients almost over the whole range of relative humidity values. Coherently with that, we see that the sample with $2 \%$ dust has slight lower diffusion coefficients that the one with no dust. This is also in line with the fact dust has retains more moisture than bonded sand [6]. 

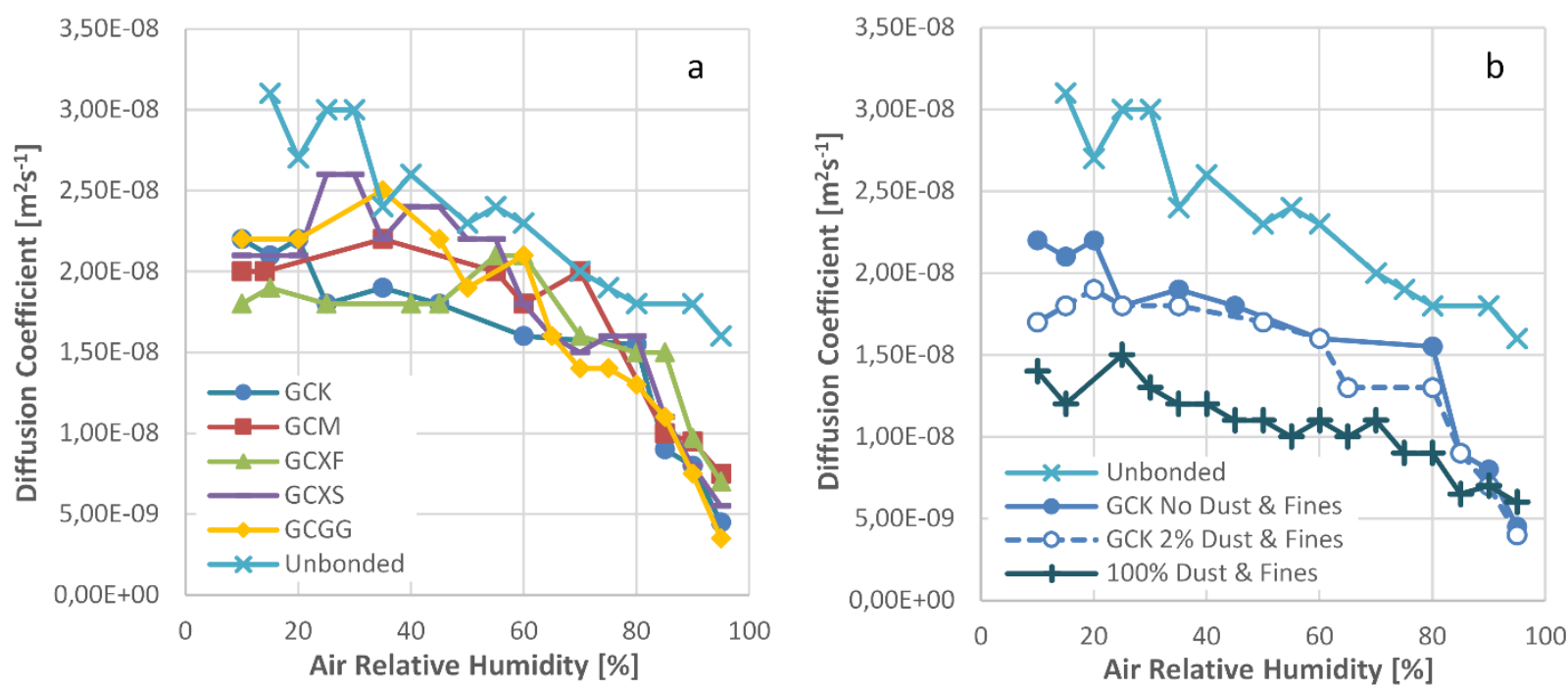

Figure 12. a) Effect of binder type and air relative humidity on moisture diffusion coefficient furan bonded sands. b) Effect of dust levels and air relative humidity on moisture diffusion coefficient of GCK furan bonded sand.

The effect of temperature in GCXF furan sand can be seen in Figure 13.a. We see that an increase in temperature form $25^{\circ} \mathrm{C}$ to $35^{\circ} \mathrm{C}$ leads to an increase of the moisture diffusion coefficient for relative humidity values below $60 \%$. A decrease in temperature from $25{ }^{\circ} \mathrm{C}$ to $15{ }^{\circ} \mathrm{C}$ does not have a significant effect of the diffusion coefficient.

Figure 13.b shows how an increase in temperature from $25^{\circ} \mathrm{C}$ to $35^{\circ} \mathrm{C}$ causes an increase in moisture diffusion coefficients for water based foundry coatings. A decrease in temperature from $25^{\circ} \mathrm{C}$ to $15^{\circ}$ shows small decrease in the diffusion coefficient values. This is in line with what is typically found in literature and practical experience (increasing temperature will speed up moisture migration).
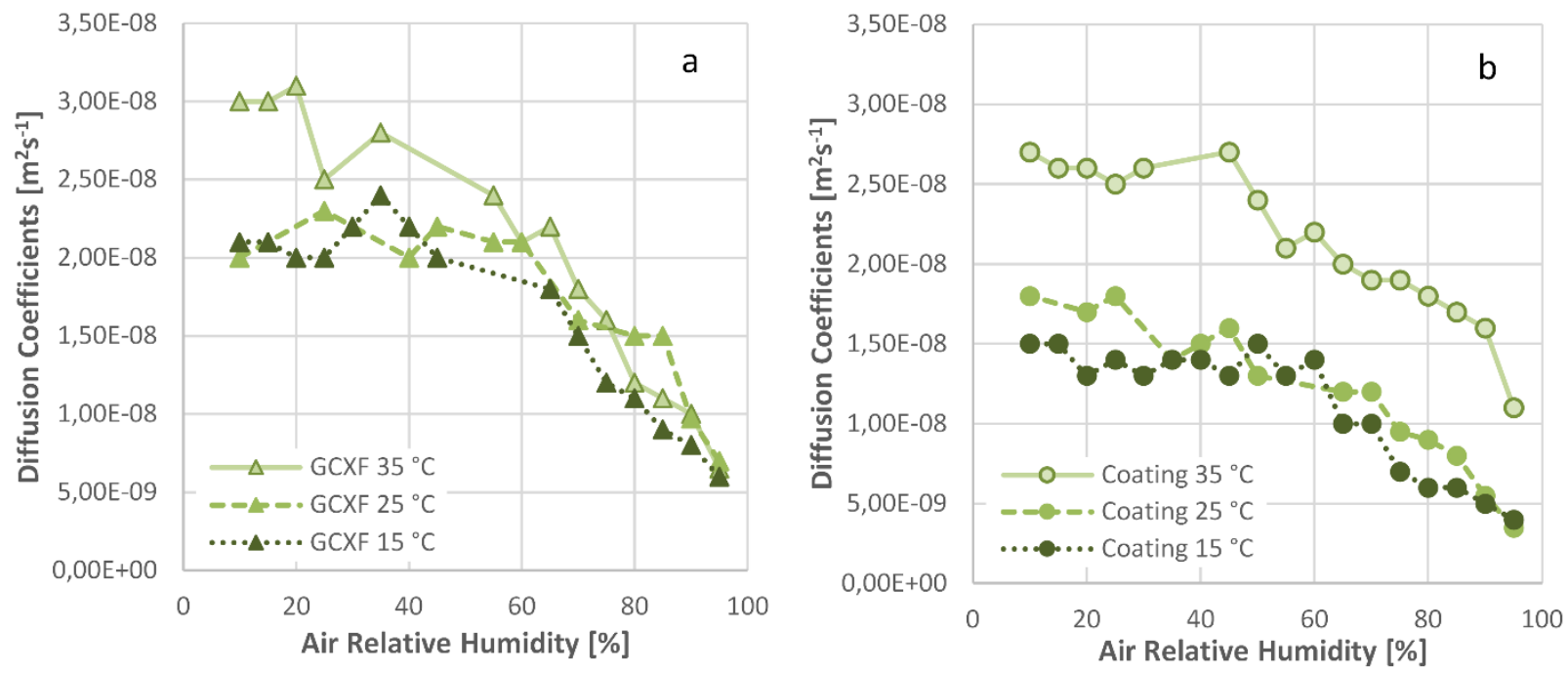
Figure 13. a) Effect of temperature and air relative humidity on moisture diffusion coefficient of GCXF furan bonded sand. b) Effect of temperature and air relative humidity on moisture diffusion coefficient of water based foundry coating.

Picture 14.a shows a typical fit of Eq.4.a and 4.b with results from manual sorption tests. We can see that there is no visible scatter, and that the solution approximates the experimental data well especially in the first part of the curve, while in the final part we have a small error. This error is most likely due to the fact that we are fitting a constant diffusion coefficient solution to a material that does not have constant diffusion coefficients.

Other possible error inherent to manual tests method can be subjected are due possible incorrect initial equilibration and lack of stability of test conditions. These will result in applying different boundary conditions to sample as compared to the one used in the mathematical model.

Picture 14.b shows a typical fit of Eq.4.a and 4.b with results from automatic sorption tests. We can see that there is more scatter in these data. Possible cause for this is the fact that we are now using smaller samples and test steps (which decrees the quantity of adsorbed water therefore reducing the relative accuracy of the weight measurement) and adding/removing dry and humid air to control the chamber conditions (therefore perturbing the air around the sample and introducing noise in the weight measurement).
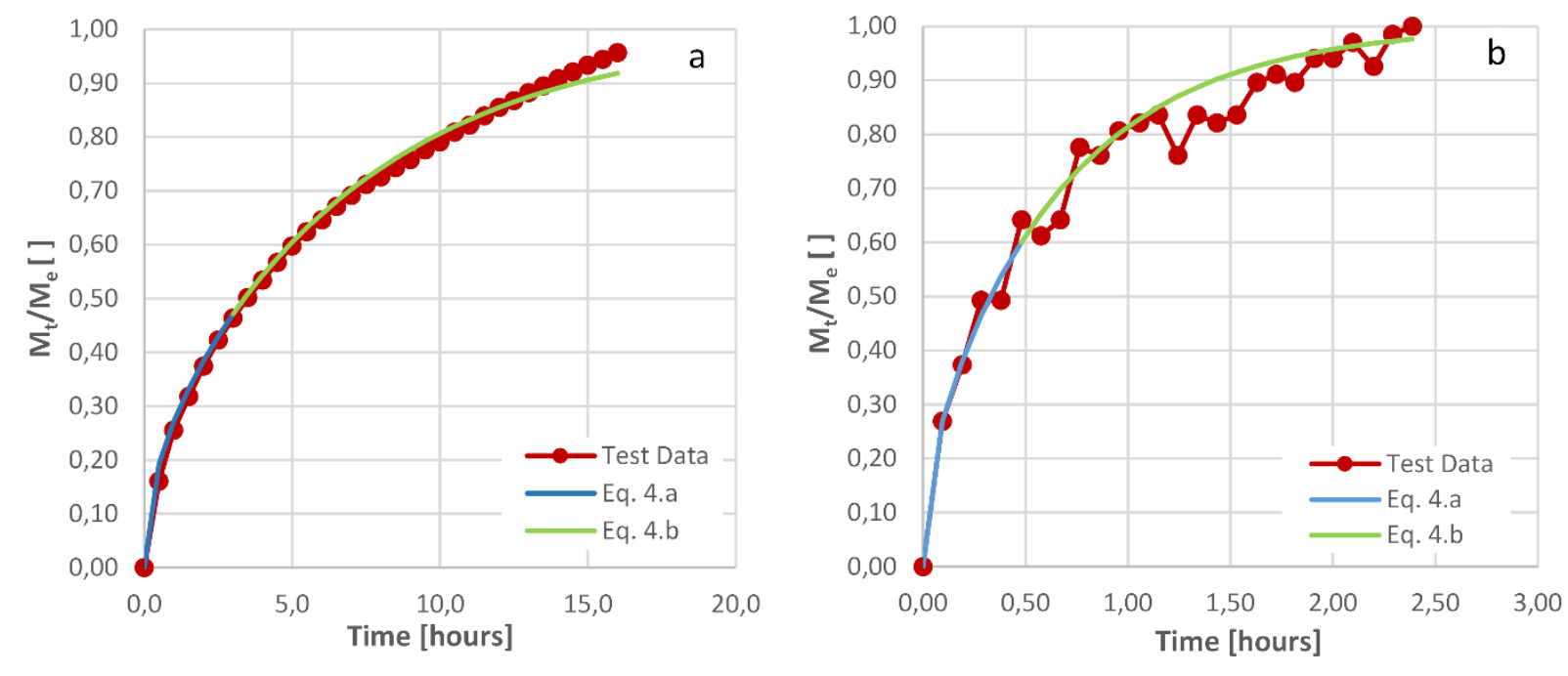

Figure 14. a) Typical fit results for a manual sorption test. b) Typical fit result for an automatic sorption test.

\section{2-Application Example}


In order to provide a practical example, we want to show how to calculate the amount of moisture that can be picked up by a square sand block of $200 \mathrm{~mm}$ in thickness and $2000 \times 2000 \mathrm{~mm}$ side dimensions of $1120 \mathrm{~kg}$ initial mass $\mathrm{M}_{\mathrm{i}}$. The calculation will per performed for cores placed in an environment at $60 \%$ or $90 \% \mathrm{RH}$ for 48 hours or 18 hours before usage.

The first step is to plot Eq. 4a and 4.b as function of time, using a thickness of $200 \mathrm{~mm}$. Based on previous test results, we use for a relative humidity of $60 \%$ a moisture diffusion coefficient of $2.00 \mathrm{E}-8 \mathrm{~m}^{2} / \mathrm{s}$, while for relative humidity of $95 \%$ a diffusion coefficient of $8.50 \mathrm{E}-9 \mathrm{~m}^{2} / \mathrm{s}$.

Figure 15 shows how the cores will reach the equilibrium moisture at a lower speed if placed in an environment at $90 \% \mathrm{RH}$ (dotted line) than compared to cores placed in an environment at $60 \% \mathrm{RH}$ (continuous line). Now, based on the production times considered ( 18 and 48 hours) we can enter the graph and extract the ratios $M_{t} / M_{e}$ between the adsorbed mass of water $M_{t}$ at the considered production time $t$ and the adsorbed mass of water at the equilibrium time $\mathrm{M}_{\mathrm{e}}$. The obtained values are reported in Table 3.

The next step, is to obtain the equilibrium moisture $X_{e}$ at the considered relative humidity of the production environment, we will use the adsorption curve for generic furan sand shown in Figure 8 and report the values in Table 3. It is important to notice that equilibrium moisture value $X_{e}$ at $95 \% \mathrm{RH}$ than is much higher $(0.70 \%)$ than that at $60 \% \mathrm{RH}(0.25 \%)$.

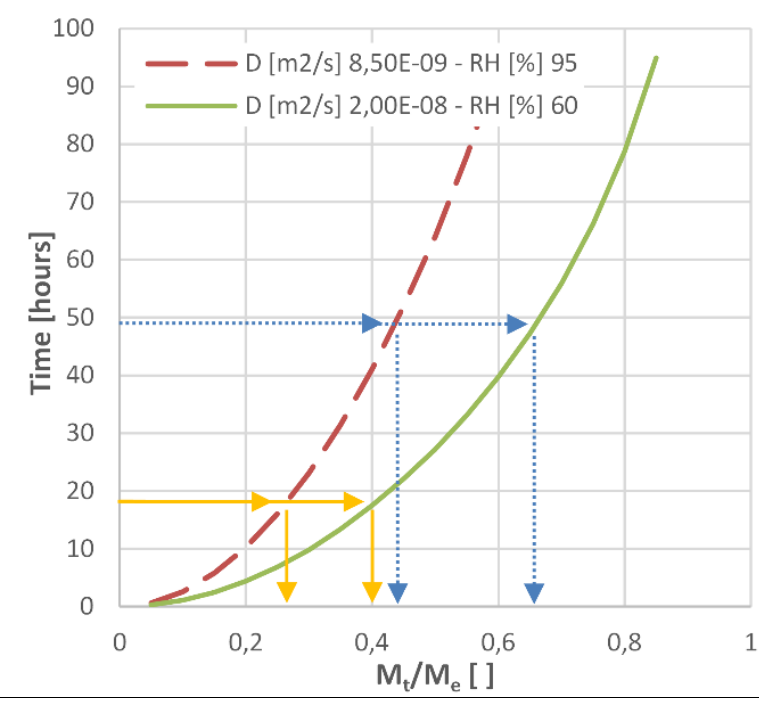

Figure 15. Adsorbed mass of water (Eq.4.a and Eq.4.b) for a core of $200 \mathrm{~mm}$ thickness in environments at $60 \%$ and $95 \%$ relative humidity.

Once we have obtained the $M_{t} / M_{e}$ ratios and the equilibrium moistures $X_{e}$ we can calculate the adsorbed mass of water $\mathrm{M}_{\mathrm{t}}$ in the different situations for the considered cores and report the values in Table 3.

The adsorbed mass $M_{t}$ of water is simply calculated as:

$M_{t}=M_{e} \frac{M_{t}}{M_{e}}=M_{i} X_{e} \frac{M_{t}}{M_{e}} \quad$ Eq. 5 
By looking at the results in Table 3 we see how a core that is left in an environment at $60 \%$ RH for only 18 hours will adsorb $1.12 \mathrm{~kg}$ of water. The same core will adsorb $1.82 \mathrm{~kg}$ of water (63\% more) if left in the same environment for 48 hours. Similarly it will adsorb $1.96 \mathrm{~kg}$ of water (75\% more) if it was left for 18 hours at $95 \% \mathrm{RH}$. The most water, $3.53 \mathrm{~kg}$ (216\% more), would be adsorbed for a core in $95 \% \mathrm{RH}$ environment for 48 hours.

We clearly notice that controlling production environment humidity to low levels and shortening the time between the completion of drying operation and use of core can substantially reduce the amount of water present in the moulds and core and therefore the risks of gas and vapour defects.

Even though the amounts of water involved in the calculation seem small we should recall that each $\mathrm{kg}$ of water will generate at least $1.7 \mathrm{~m}^{3}$ of water vapour when it will come in contact with the melt and heat up to $100^{\circ} \mathrm{C}$.

Table 3. Summary of moisture pick-up parameters and adsorbed mass of water $\mathbf{M}_{t}$ for a core of dimensions $200 \times 2000 \times 200 \mathrm{~mm}$, initial mass $M_{i}$ of $1120 \mathrm{~kg}$ placed in production in environments at $60 \%$ and $95 \%$ relative humidity for 18 hours and 48 hours.

\begin{tabular}{|c|c|c|c|c|c|c|c|}
\hline & & \multirow[t]{2}{*}{$\mathrm{X}_{\mathrm{e}}$ [\%] } & \multirow{2}{*}{$\begin{array}{c}\mathrm{Me}_{\mathrm{e}} \\
{[\mathrm{kg}]}\end{array}$} & $\begin{array}{c}\mathbf{M}_{\mathrm{t}} / \mathbf{M}_{\mathbf{e}} \\
\text { [] }\end{array}$ & $\begin{array}{c}\mathrm{M}_{\mathrm{t}} \\
{[\mathrm{kg}]}\end{array}$ & $\begin{array}{c}\mathrm{M}_{\mathrm{t}} / \mathrm{M}_{\mathrm{e}} \\
\text { [ ] }\end{array}$ & $\begin{array}{c}\mathrm{Mt}_{\mathrm{t}} \\
{[\mathrm{kg}]}\end{array}$ \\
\hline & & & & \multicolumn{2}{|c|}{18 hours } & \multicolumn{2}{|c|}{48 hours } \\
\hline \multirow{2}{*}{$\begin{array}{c}\text { RH } \\
\text { [\%] }\end{array}$} & 60 & 0.25 & 2.8 & 0.40 & 1.12 & 0.65 & 1.82 \\
\hline & 95 & 0.70 & 7.8 & 0.25 & 1.96 & 0.45 & 3.53 \\
\hline
\end{tabular}

\section{4 - Conclusions}

The main conclusions that we can draw from this study can be summarised as below:

- Two different tests methodologies (manual and automatic method) for testing water adsorption diffusion coefficients of foundry sands and coatings were compared, similar values of diffusion coefficients we obtained from both methodologies

- Manual method has a lower cost and longer test times, but diffusion coefficients can be overestimated for relative humidities above $60 \%$ for the tested sands, and, in general, whenever material will have a moisture diffusion coefficient which is a function of moisture content there will be some error

- Automatic tests require the most expensive equipment, but it is possible to determine diffusion coefficients from $3 \%$ to $95 \%$ relative humidity in short amount of time

- Diffusion coefficients have been obtained for both furan sands and foundry coatings, these coefficients can be used in hand calculation as well as in 3D simulation software

- Comparison with other ceramic materials available in literature (like concrete, clay and sand) was carried out showing that foundry sands and coating have diffusion coefficients of similar order of magnitude

- Sand density effect on moisture diffusion coefficient is minor for sand densities around $1100 \mathrm{~kg} / \mathrm{m}^{3}$ and not appreciable for densities between $1250 \mathrm{~kg} / \mathrm{m}^{3}$ and $1550 \mathrm{~kg} / \mathrm{m}^{3}$ 
- Binder type can influence moisture diffusion coefficients so this could be used as a criteria for selecting binders when gas problems are encountered

- Dust can decrease moisture diffusion coefficients but in the quantities smaller than $2 \%$ it does not play a major role

- Temperature increase from $25^{\circ} \mathrm{C}$ to $35^{\circ} \mathrm{C}$ will increase moisture diffusion coefficients especially for coating

- A simple hand calculation methodology to estimate moisture content of foundry sand cores was introduced and applied to a real case

- The tests and calculation example show that it is possible to lower moisture in cores and moulds by properly controlling time, relative humidity, binder type and temperature

\section{5 - Acknowledgments}

This work was financed by Global Castings A/S, the Danish Agency for Science, Technology and Innovation (DASTI) and the Technical University of Denmark (DTU). LabCell Ltd. provided support in executing the tests on the automatic vapour sorption analyser.

\section{6 - References}

1 - J. Campbell, R.A. Harding: 'Solidification Defects in Castings', Lecture 3207, The University of Birmingham, 4-8, 1994.

2 - L. Elmquist: 'Defect formation in cast iron', Presentation, School of Engineering, Jonkoping University, Sweden, 2012.

3 - IKO: 'Description of Casting Defects', Chapters 04,10,12, S\&B Industrial Minerals

4 - A. Chojecki*, J. Mocek: 'Effect of atmosphere in a foundry mould on casting surface quality', Archives of Foundry Engineering, Volume 12, Issue 1/2012, 13-18.

5 - D - Elkem: 'Hydrogen Pinholes', Technical Information 30, Elkem Foundry Products, Rev. 1.2, 2007.

6 - G.L. Di Muoio, N. Skat Tiedje and B. Budolph Johansen: 'Automatic vapour sorption analysis as new methodology for assessing moisture content of water based foundry coating and furan sands', 10th International Symposium on the Science and Processing of Cast Iron - SPCI10, 2014 November, Argentina, Mar de Plata.

7 - A.S. Mujumdar: 'Handbook of industrial drying', 3rd edition, Ch. 3-4, 2006.

8 - I. Boulaoued, Abdallah Mhimid: 'Determination of the diffusion coefficient of new insulators composed of vegetable fibers', Thermal Science, Year 2012, Vol. 16, No. 4, pp. 987-995.

9 - J. Carmeliet, * H. Hens, S. Roels: 'Determination of the Liquid Water Diffusivity from Transient Moisture Transfer Experiments', Journal of Thermal Env. \& Bldg. Sci., Vol. 27, No. 4-April 2004. 
10 - JEDEC Solid State Technology Association: 'Test Method for the Measurement of Moisture Diffusivity and Water Solubility in Organic Materials Used in Electronic Devices', JESD22-A120A, January 2008.

11 - D. Gaffner: 'The Moment Method for Measuring Moisture Diffusivity of Porous Building Materials', Bulding X, 2007 ASHRAE.

12 - L. Hassini, S. Azzouz, R. Peczalski, A. Belghith: 'Estimation of potato moisture diffusivity from convective drying kinetics with correction for shrinkage', Journal of Food Engineering, Volume 79, Issue 1, March 2007, Pages 47-56.

13 - M. Janz: 'Methods of measuring the moisture diffusivity at high moisture levels', Report TVBM-3076, University Of Lund, Lund Institute Of Technology, Division of Building Materials, Licentiate Thesis, Lund ,1997.

14 - G. L. Di Muoio, N. Skat Tiedje, B. Budolph Johansen: 'Critical Control Variables For The Coating Process Of Furan Bonded Sand With Water Based Foundry Coatings', $71^{\text {st }}$ World Foundry Congress, Bilbao, May 2014.

15 - X. Chen, S. Zhao: 'Moisture Absorption and Diffusion Characterization of Molding Compound', Transactions of the ASME, 460 / Vol. 127, December 2005.

16 - E. Celik, I. Guven, and E. Madenci: 'Experimental and Numerical Characterization of NonFickian Moisture Diffusion in Electronic Packages', 1-4244-0985-3/07, IEEE, Electronic Components and Technology Conference, 2007. 


\section{Figure Captions}

Figure 1. Example of Moisture Related Defect.

Figure 2. Production process steps for a furan sand mould coated with water based coating and correspondent ranges of environment conditions.

Figure 3. Sample Preparation for manual adsorption tests.

Figure 4. Schematic test setup for manual sorption tests.

Figure 5. Sample preparation for automatic vapour sorption tests.

Figure 6. Test setup schematic for automatic sorption tests.

Figure 7. Typical data output from and automatic sorption test run.

Figure 8. Typical adsorption/desorption curve for furan sand.

Figure 9. Example of experimental data fitted with the two approximated solutions Eq.4a and Eq4.b.

Figure 10. Density effect on moisture diffusion coefficient obtained with manual test method.

Figure 11. Effect of test method and air relative humidity on moisture diffusion coefficient of GCK and GCM furan sands.

Figure 12. a) Effect of binder type and air relative humidity on moisture diffusion coefficient furan bonded sands. b) Effect of dust levels and air relative humidity on moisture diffusion coefficient of GCK furan bonded sand.

Figure 13. a) Effect of temperature and air relative humidity on moisture diffusion coefficient of GCXF furan bonded sand. b) Effect of temperature and air relative humidity on moisture diffusion coefficient of water based foundry coating.

Figure 14. a) Typical fit results for a manual sorption test. b) Typical fit result for an automatic sorption test.

Figure 15. Adsorbed mass of water (Eq.4.a and Eq.4.b) for a core of $200 \mathrm{~mm}$ thickness in environments at $60 \%$ and $95 \%$ relative humidity. 


\section{Table Captions}

Table 1. Overview of experimental plan for manual sorption tests.

Table 2. Overview of experimental plan for automatic vapour sorption tests.

Table 3. Summary of moisture pick-up parameters and adsorbed mass of water $M_{t}$ for a core of dimensions $200 \times 2000 \times 200 \mathrm{~mm}$, initial mass $M_{i}$ of $1120 \mathrm{~kg}$ placed in production in environments at $60 \%$ and $95 \%$ relative humidity for 18 hours and 48 hours. 